Pesq. Vet. Bras. 38(4):751-761, abril 2018

\title{
Graduação histológica e aspectos clínico-patológicos relacionados em 22 meningiomas de cães ${ }^{1}$
}

\author{
Walter V. Cardozo Areco², Taiara M. Silva², Stella M.P. Melo³, \\ Marcia C. Silva ${ }^{4}$, Luiz Francisco Irigoyen ${ }^{4}$, Rafael A. Fighera ${ }^{4}$, Alexandre Mazzanti ${ }^{5}$ \\ e Glaucia D. Kommers ${ }^{4 *}$
}

\begin{abstract}
Cardozo Areco W.V., Silva T.M., Melo S.M.P., Silva M.C., Irigoyen L.F., Fighera R.A., Mazzanti A. \& Kommers G.D. 2018. [Histological grading and related clinical and pathological aspects of 22 canine meningioma.] Graduação histológica e aspectos clínico-patológicos relacionados em 22 meningiomas de cães. Pesquisa Veterinária Brasileira 38(4):751-761. Laboratório de Patologia Veterinária, Departamento de Patologia, Universidade Federal de Santa Maria, Camobi, Santa Maria, RS 97105-900, Brazil. E-mail: glaukommers@yahoo.com

Twenty two cases of meningiomas in dogs, diagnosed in about 18 years, were analyzed. The neoplasms were histologicaly classified and graded according to the World and Health Organization (WHO of 2007) for human meningiomas, adapted for dogs, in Grade I (G-I; benign), Grade II (G-II; atypical), and Grade III (G-III; anaplastic or malignant). Additional data about gender, age, breed, skull conformation, clinical course and signs, anatomic localization, gross and histological findings were obtained from the necropsy reports. Intracranial and supratentorial meningiomas were the most frequent in relation to the other intracranial or intraspinal sites. The intracranial ones were characterized mainly by clinical signs of thalamic-cortical alteration. Intraspinal ones were mainly characterized by ataxia. G-I meningiomas were the most frequent (63.6\%) in dogs, followed by G-III (22.7\%) and G-II (13.6\%). GI were characterized by having the psammomatous subtype as the most frequent, more than one morphological pattern in the same tumor, one third presenting areas of invasion of nervous tissue, $71.4 \%$ of cases involving females, a mean age of 11 years, pure breed dogs as the most affected ones and for having the longest survival time after the manifestation of clinical signs. G-II meningiomas were characterized by having the chordoid subtype as the most frequent, invasion of nervous tissue in one third of cases, only females affected, a mean age of 12 years, two-thirds of the dogs affected were mongrels and the maximum survival time of 20 days. The G-III meningiomas were characterized by having the papillary subtype as the most frequent, invasion of the nervous tissue in $80 \%$ of the cases, $60 \%$ of the cases involving females, a mean age of 8 years, $80 \%$ of dogs affected were Boxers and the maximum survival time of 90 days. In conclusion, this study allowed to establish a relationship between the three histological grades observed in 22 cases of meningiomas in dogs with various clinical-epidemiological and pathological parameters, providing useful information for a better understanding of the correlation between the histological grading and the clinical evolution of these neoplasms.
\end{abstract}

INDEX TERMS: Meningioma, brain neoplasms, histological gradind, dogs, pathology.

\footnotetext{
${ }^{1}$ Recebido em 24 de fevereiro de 2017.

Aceito para publicação em 26 de março de 2017.

${ }^{2}$ Programa de Pós-Graduação em Medicina Veterinária, área de concentração em Patologia e Patologia Clínica Veterinária, Centro de Ciências Rurais (CCR), Universidade Federal de Santa Maria (UFSM), Av. Roraima 1000, Camobi, Santa Maria, RS 97105-900, Brasil.

${ }^{3}$ Curso de Medicina Veterinária, Centro de Ciências Rurais (CCR), Universidade Federal de Santa Maria (UFSM), Av. Roraima 1000, Camobi, Santa Maria, RS 97105-900.
}

\footnotetext{
${ }^{4}$ Laboratório de Patologia Veterinária, Departamento de Patologia, Centro de Ciências da Saúde, Universidade Federal de Santa Maria (UFSM), Av. Roraima 1000, Camobi, Santa Maria, RS 97105-900. *Autor para correspondência: glaukommers@yahoo.com

${ }^{5}$ Departamento de Clínica de Pequenos Animais (DCPA), Centro de Ciências Rurais (CCR), Universidade Federal de Santa Maria (UFSM), Av. Roraima 1000, Camobi, Santa Maria, RS 97105-900.
} 
RESUMO.- Vinte e dois casos de meningiomas em cães, diagnosticados num período de aproximadamente 18 anos, foram revisados. Os neoplasmas foram graduados e classificados histologicamente de acordo com os critérios da Organização Mundial da Saúde (OMS de 2007) para meningiomas em humanos adaptados para cães, em Grau I (G-I; benignos), Grau II (G-II; atípicos) e Grau III (G-III; anaplásico ou maligno). Dos protocolos de necropsias foram retiradas adicionalmente informações referentes ao sexo, idade, raça, evolução clínica, sinais clínicos, localização anatômica e achados macroscópicos. Os meningiomas intracranianos supratentoriais foram os mais frequentes em relação às demais localizações intracranianas ou intraespinhais. Os intracranianos caracterizaram-se principalmente por sinais clínicos de alteração tálamo-cortical. Os intraespinhais caracterizaram-se principalmente por causarem ataxia. Meningiomas G-I foram os mais frequentes $(63,6 \%)$ nos 22 cães, seguidos pelos G-III $(22,7 \%)$ e G-II $(13,6 \%)$. Os G-I caracterizaram-se por ter o subtipo psammomatoso como o mais frequente, mais de um padrão morfológico em um mesmo tumor, e um terço deles apresentando áreas de invasão do tecido nervoso, 71,4\% dos casos acometendo fêmeas, uma média de idade de 11 anos, cães com raça definida como os mais acometidos e por ter o maior tempo de sobrevivência após a manifestação dos sinais clínicos. Os meningiomas G-II caracterizaram-se por ter o subtipo cordoide como o mais frequente, invasão do tecido nervoso em um terço dos casos, somente fêmeas acometidas, uma média de idade de 12 anos, dois terços dos cães acometidos sem raça definida e o tempo máximo de sobrevivência de 20 dias. Os meningiomas G-III caracterizaram-se por ter o subtipo papilar como o mais frequente, invasão do tecido nervoso em $80 \%$ dos casos, $60 \%$ dos casos acometendo fêmeas, uma média de idade de 8 anos, $80 \%$ dos cães acometidos da raça Boxer e o tempo máximo de sobrevivência de 90 dias. Este estudo permitiu estabelecer uma relação entre os três graus histológicos observados em 22 casos de meningiomas em cães com vários parâmetros clínico-epidemiológicos e patológicos, fornecendo informações úteis para um melhor conhecimento da correlação entre a graduação histológica e a evolução clínica desses neoplasmas.

TERMOS DE INDEXAÇÃO: Meningiomas, neoplasmas encefálicos, graduação histológica, caninos, doenças de cães, patologia.

\section{INTRODUÇÃO}

Na rotina do Laboratório de Patologia Veterinária da Universidade Federal de Santa Maria (LPV-UFSM), neoplasmas representam a segunda causa de morte ou razão para eutanásia de cães da Mesorregião do Centro Ocidental Rio-Grandense, atrás apenas das doenças infecciosas, perfazendo 7,8\% dos casos (Fighera et al. 2008). A maior parte dos neoplasmas primários do SNC de cães da rotina de diagnóstico do LPV-UFSM são meningiomas $(44,4 \%)$ (Fighera et al. 2008). Em contraste com estudos europeus, em que os gliomas são os mais prevalentes em cães (Summers et al. 1995, Koestner \& Higgins 2002). Meningioma é um neoplasma do sistema nervoso central (SNC) que se origina das células meningoteliais das leptomeninges, que na maioria são considerados benignos do ponto de vista histológico, mas pelo crescimento dentro do espaço intracraniano e subdural, geram consequências malignas do ponto de vista biológico (Costa
2009). Nos Estados Unidos é o tumor primário do SNC mais comum em cães (40\% dos tumores primários) (Snyder et al. 2006, Vandevelde et al. 2012) e gatos (Troxel et al. 2004), e são relatados esporadicamente em cavalos (Kreeger et al. 2002), bovinos (Josephson \& Little 1990) e ovinos (Koestner \& Higgins 2002, Vandevelde et al. 2012).

Meningiomas em humanos e animais domésticos são histologicamente variados e podem sofrer diferenciação epitelial ou mesenquimal (Summers et al. 1995, Koestner \& Higgins 2002). Essa variedade histológica é reflexo da contribuição do mesoderma e da crista neural para a sua formação (Koestner \& Higgins 2002). Não há predisposição sexual em cães (Patnaik et al. 1986), entretanto, mulheres apresentam maior incidência de meningiomas (Koestner \& Higgins 2002, Montoliu et al. 2006).

Pela classificação da Organização Mundial da Saúde (OMS) de 1999 (Koestner et al. 1999) dos tumores do SNC de animais domésticos, os meningiomas de cães são dividos histologicamente em dois grupos principais: benignos, aqueles de crescimento lento de vários subtipos (meningotelial, fibroblástico, transicional, psamomatoso, angiomatoso, papilar, de células granulares e mixoide) e anaplásicos (malignos) (Koestner et al. 1999). 0 subtipo microcístico foi posteriormente identificado de forma independente (Montoliu et al. 2006).

Não há dados disponíveis na literatura correlacionando o comportamento biológico e a evolução clínica com o sistema de classificação da OMS de 1999 (Koestner et al. 1999) para meningiomas em cães. Em humanos, um sistema de classificação mais detalhado permite a correlação consistente dos achados histológicos com o comportamento biológico dos meningiomas (Sturges et al.2008). Um componente importante deste sistema de classificação é o agrupamento dos meningiomas em três graus histológicos, Grau I (benigno), Grau II (atípico) e Grau III (maligno ou anaplásico), que é fundamental para prever o comportamento clínico e a evolução clínica nos humanos (Louis et al. 2007).

A partir de 2008, vários autores (Petersen et al. 2008, Sturges et al. 2008, Vandevelde et al. 2012, Cantile \& Youssef 2016) passaram a classificar os meningiomas de cães através do sistema de graduação adaptado daquele utilizado para humanos pela OMS de 2007 (Louis et al. 2007). Pelo fato de meningiomas caninos serem histologicamente muito semelhantes aos seus homólogos de humanos, indicadores preditivos e prognósticos clínicos utilizados em pessoas podem ser valiosos no tratamento de cães com meningiomas (Sturges et al. 2008).

$\mathrm{Na}$ rotina diagnóstica busca-se adotar esquemas de classificação de tumores que permitam uma boa correlação entre a classificação histológica e o prognóstico, melhorando a sua aplicabilidade prática. Como no Brasil a terapia oncológica em geral para cães tem ampliado sua utilização, há cada vez mais uma demanda para o tratamento de meningiomas, baseado em seu comportamento biológico.

Com base nessa problemática, este estudo retrospectivo teve como objetivo principal classificar e graduar 22 meningiomas diagnosticados em cães necropsiados ao longo de aproximadamente 18 anos no LPV-UFSM através do sistema de graduação histológica proposto na literatura internacional para cães (Petersen et al. 2008, Sturges et al. 2008, Vandevelde et al. 2012, Cantile \& Youssef 2016), adaptado do utilizado para 
humanos pela OMS de 2007 (Louis et al. 2007). Os resultados serão computados e relacionados aos aspectos epidemiológicos, clínicos e anatomopatológicos. Os dados obtidos serão comparados ao que é descrito na literatura para meningiomas de cães e humanos, a fim de fornecer subsídios para clínicos e patologistas veterinários no que se refere a esse neoplasma.

\section{MATERIAL E MÉTODOS}

Os casos de meningiomas diagnosticados em cães no LPV-UFSM, entre janeiro de 1999 e abril de 2016 (18 anos e 13 meses) foram revisados. Este estudo foi dividido em quatro etapas: (1) separação e análise dos protocolos de necropsia, (2) catalogação dos dados, (3) reavaliação histológica e (4) graduação histológica de acordo com Petersen et al. (2008), Sturges et al. (2008), Vandevelde et al. (2012) e Cantile \& Youssef (2016). Dos protocolos de necropsia foram retiradas informações referentes ao sexo e ao status reprodutivo (se eram castrados ou não), idade, raça (com ou sem raça definida [SRD] e conformação do crânio [dolicocefálicos, braquicefálicos ou mesocefálicos]), sinais clínicos, evolução clínica (após o início dos sinais clínicos), ocorrência de tratamento clínico, localização anatômica, achados macroscópicos e histológicos.

Os meningiomas foram descritos de acordo com sua localização anatômica intracraniana como das regiões: olfatória, convexidade do cérebro, parasselar, parassagital, falcino, tentorial e do ângulo ponto-cerebelar, de acordo com Sturges et al. (2008). A origem do tumor (OT) para cada região foi: região olfatória (OT: lâmina crivosa, osso pré-esfenoide, crânio ventral se estendendo ao osso frontal), parasselar (OT: osso basoesfenoide, fossa hipofisiária, tubérculo selar, seio cavernoso), parassagital (OT: ângulo parassagital [o espaço formado pela convexidade da dura-máter e a parede lateral da foice cerebral]), falcino (OT: foice cerebral [tumores completamente escondidos pelo córtex cerebral sobreposto]), convexidade do cérebro (OT: convexidade cerebral frontal, parietal, occipital e temporal), tentorial (OT: região do osso tentório), ângulo ponto-cerebelar. Na medula espinhal, os meningiomas foram descritos de acordo com sua localização anatômica em segmentos C1-C5, C6-T1 e T2-T5 (Petersen et al. 2008).

Os sinais clínicos foram agrupados conforme as manifestações clínicas neurológicas, de acordo com Costa (2009), e incluíram: alterações tálamo-corticais, vestibulares centrais e medulares. Os achados histológicos reavaliados em cada caso incluíram: (1) arranjo celular, (2) padrão estromal (escasso ou abundante), (3) índice mitótico, (4) atipia nuclear, (5) presença de células pequenas, (6) pleomorfismo celular, (7) invasão vascular e/ou do parênquima adjacente, (8) necrose, hemorragia e inflamação em meio ao tumor e (9) alterações no tecido nervoso adjacente ao tumor. De forma geral, esses aspectos histológicos fazem parte das características contempladas na descrição de meningiomas (Petersen et al. 2008, Sturges et al. 2008, Vandevelde et al. 2012, Cantile \& Youssef 2016). Os meningiomas foram graduados histologicamente e classificados em subtipos de acordo com os critérios da OMS de 2007 para meningiomas em humanos (Louis et al. 2007), adaptados às características histológicas de meningiomas em cães (Petersen et al. 2008, Sturges et al. 2008, Vandevelde et al. 2012, Cantile \& Youssef 2016). A graduação compreendeu: Grau I (G-I, benignos), Grau II (G-II, atípicos) e Grau III (G-III, maligno ou anaplásico). Os meningiomas de G-I foram classificados nos subtipos histológicos meningotelial, transicional, microcístico, fibroblástico e psamomatoso. Os meningiomas de G-II foram classificados nos subtipos atípico e cordoide. Os G-III foram classificados nos subtipos papilar e maligno.

\section{RESULTADOS}

Os resultados referentes aos aspectos clínico-epidemiológicos, achados de necropsia e achados histopatológicos serão apresentados baseados nos graus histológicos, sendo que os meningiomas foram classificados em: G-I (14 casos), G-II (3 casos) e G-III (5 casos).

\section{Achados clínico-epidemiológicos}

Entre janeiro de 1999 e abril de 2016 foram realizadas 4.893 necropsias de cães no LPV-UFSM. Nesse período, 22 cães $(0,4 \%)$ foram diagnosticados com meningioma. Desses, 16 eram fêmeas (72,7\%; 2/16 castradas) e seis eram machos (27,3\%; $1 / 6$ castrado), com idades que variaram entre 5 e 15 anos. A média de idade foi de 11 anos para cães com meningioma GI, 12 anos para os com G-II e 8 anos para os com G-III. Quanto à raça, 16 (72,7\%) eram de raça e 6 (27,3\%) eram SRD. As raças incluíram: Boxer (7/16; 43,7\%), Pastor Alemão (4/16; 25\%), Rottweiler (3/16; 18,7\%), Dachshund $(1 / 16 ; 6,2 \%)$ e Poodle $(1 / 16 ; 6,2 \%)$. Quanto à conformação do crânio dos cães de raça, 7/16 eram braquicéfalos, 5/16 eram dolicocéfalos e 4/16 eram mesocéfalos. As informações detalhadas de cada caso estão no Quadro 1.

Quanto ao quadro clínico, baseado na localização, 65\% dos casos (13/20) manifestaram sinais de alterações tálamo-corticais, 20\% (4/20) de alterações vestibulares centrais e 15\% (3/20) de alterações medulares (Quadros 1 e 2). Em dois casos não havia informações sobre o quadro clínico. Quanto ao tratamento, em 12 casos ( 8 de G-I, 2 de G-II e 2 de G-III) havia informação de os cães terem sido tratados. Esses tratamentos incluíam a utilização de corticoides e anticonvulsivantes.

Com relação ao desfecho clínico, 12/22 cães foram submetidos à eutanásia e em 9/22 a morte foi espontânea. Em um caso, não havia informação. Independentemente do desfecho, a evolução clínica variou de poucos dias até 1 ano para os cães com meningiomas de G-I, de 7 a 20 dias para os de G-II e de 30 a 90 dias para os de G-III (Quadro 1).

\section{Achados de necropsia}

Com relação à localização, 4/22 foram na região olfatória, 4/22 na região parassagital, $3 / 22$ na convexidade do cérebro, $3 / 22$ na região parasselar, $2 / 22$ foram tentoriais, $2 / 22$ no ângulo ponto-cerebelar, $1 / 22$ no falcino e $3 / 22$ na medula espinal.

Os meningiomas G-I se apresentaram como intracranianos em 12/14 casos, sendo de localização parassagital em $4 / 12$, olfatória em 3/12 (2/3 estendiam-se para os seios paranasais), na convexidade do cérebro em $2 / 12$, parasselar em 1/12 (afetando o nervo óptico), falcino em 1/12 e tentorial (1/12). Os intraespinhais foram $2 / 14$ e vistos na medula espinhal C6-T1 e T2. Os G-I se apresentaram principalmente na forma de massa (12/14) e em placa (2/14). Os meningiomas em forma de massa variaram entre 0,3 x 0,6 x 0,7cm a $4,0 \times 2,0 \times 2,0 \mathrm{~cm}$. Eram branco-acinzentados (11/12) ou avermelhados (1/12), macios (4/12) ou firmes $(8 / 12) \mathrm{e}$ alguns tinham áreas císticas $(2 / 12)$. Aqueles descritos como placas (2/14) mediram entre 1,0 e 1,5cm em seu maior eixo, e tinham localização parasselar (1/2; afetando o nervo óptico) ou parassagital (1/2). Eram branco-acinzentados $(1 / 2)$, avermelhados (1/2) e firmes $(2 / 2)$.

Todos os meningiomas G-II foram descritos como massas (3/3) tinham entre $2,5 \times 2 \times 1 \mathrm{~cm}$ e $3 \times 2 \times 1,5 \mathrm{~cm}$; eram brancacentos 
Quadro 1. Aspectos epidemiológicos, clínicos e patológicos de meningiomas em 22 cães

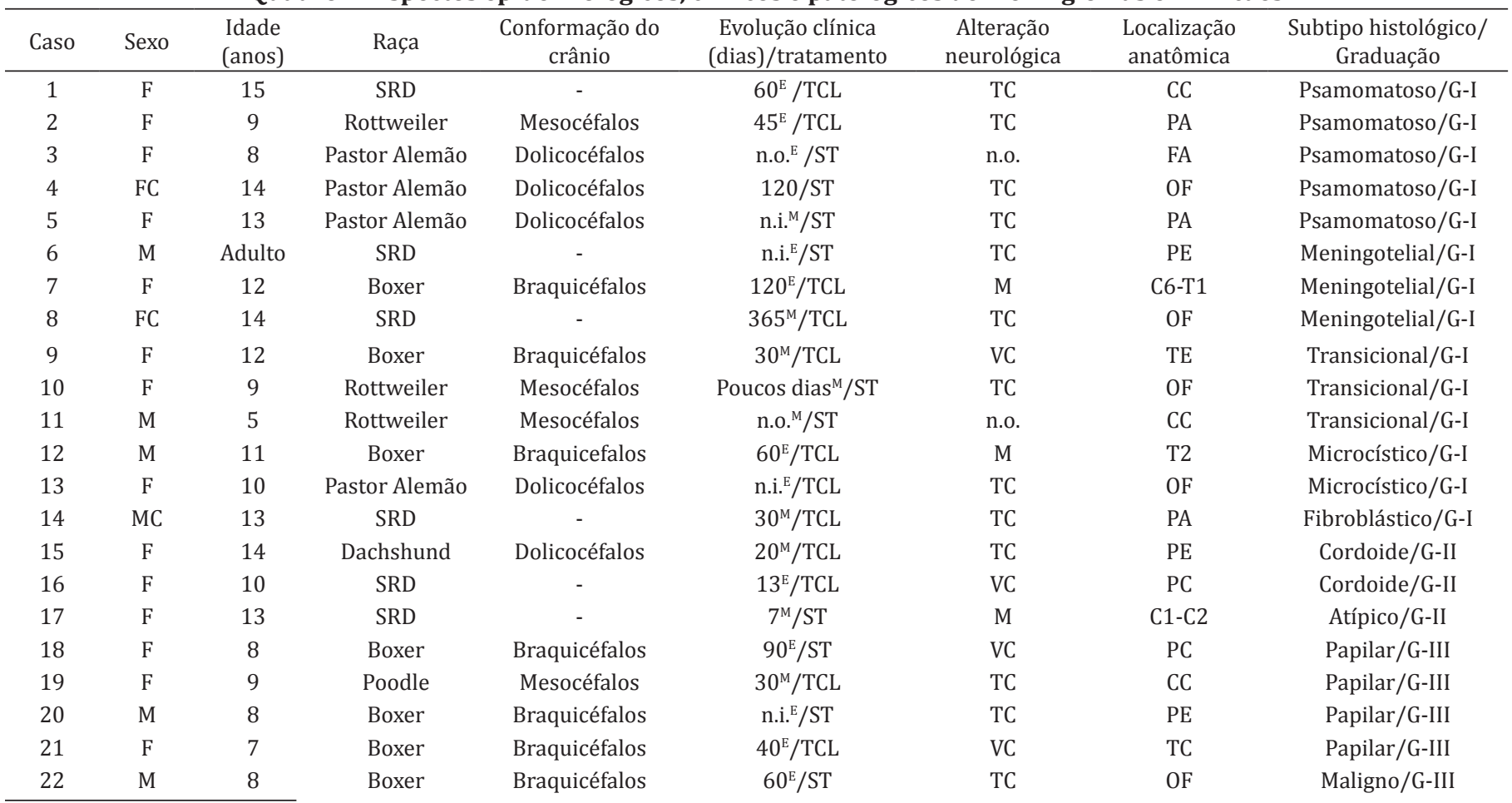

$\mathrm{F}$ = fêmea, $\mathrm{FC}=$ fêmea castrada, $\mathrm{M}=$ macho, $\mathrm{MC}=$ macho castrado, $\mathrm{SRD}=$ sem raça definida, $\mathrm{E}=$ eutanásia, $\mathrm{M}=$ morte espontânea, n.i. = não informado, n.o.= não observado, $\mathrm{TC}=$ tálamo-cortical, $\mathrm{M}=$ medular, $\mathrm{VC}=$ vestibular central, $\mathrm{CC}=$ convexidade do cérebro, $\mathrm{OF}=$ olfatória, $\mathrm{PE}=$ parasselar, $\mathrm{PA}=$ parassagital, $\mathrm{FA}=$ falcino, $\mathrm{TE}=$ tentorial, $\mathrm{PC}=$ ângulo ponto-cerebelar, $\mathrm{TCL}=$ tratamento clínico, $\mathrm{ST}=$ sem tratamento.

Quadro 2. Manifestações clínicas neurológicas observadas em cães com meningiomas

\begin{tabular}{lc}
\hline \multicolumn{1}{c}{ Tipos de alterações } & Número de casos \\
\hline Alterações tálamo-corticais (TC*) & $\mathbf{N}=\mathbf{1 3}$ \\
Crise convulsiva & $10 / 20$ \\
Ausência de reações (reação à ameaça, déficit & $7 / 20$ \\
proprioceptivo, alteração nos testes do salto e & \\
hemissalto) & $5 / 20$ \\
Alteração do nível de consciência & $3 / 20$ \\
Andar em círculo & $2 / 20$ \\
Mudança de comportamento (agressividade) & $1 / 20$ \\
Andar compulsivo & $1 / 20$ \\
Déficit visual & $1 / 20$ \\
Compressão da cabeça contra objetos & \\
& $\mathbf{N}=\mathbf{4}$ \\
Alterações vestibulares centrais (VC*) & $2 / 20$ \\
Déficit de pares cranianos (V, VII, IX, X e XII) & $1 / 20$ \\
Ataxia (tipo vestibular) & $1 / 20$ \\
Andar em círculos pequenos & $1 / 20$ \\
Nistagmo (horizontal) & $1 / 20$ \\
Déficit proprioceptivo & $1 / 20$ \\
Alteração do nível de consciência & \\
& $\mathbf{N}=\mathbf{3}$ \\
Alterações medulares (M*) & $2 / 20$ \\
Ataxia (tipo proprioceptiva) & $2 / 20$ \\
Dor à palpação do segmento afetado & $1 / 20$ \\
Déficit proprioceptivo & $1 / 20$ \\
Paresia/paralisia & \\
* TC = cães 1, 2, 4, 5, 6, 8, 10, 13, 14, 15, 19, 20, 22; VC = cães $9,16,18,21 ;$ \\
M = cães 7, 12, 17.
\end{tabular}

ou acinzentados (2/3) ou avermelhados (1/3) e macios (3/3). Eram intracranianos (vistos no ângulo ponto-cerebelar (1/3) e região parasselar (1/3) ou intraespinhais (vistos na medula espinhal C1-C2 [1/3]).

Os meningiomas G-III foram vistos na forma de massas $(4 / 5)$ e placas (1/5). Os meningiomas em forma de massa variaram entre $1 \times 1,5 \times 0,5 \mathrm{~cm}$ a $4 \times 2 \times 0,5 \mathrm{~cm}$ e todos eram intracranianos, com localização olfatória (1/4), parasselar (1/4), tentorial (1/4) e no ângulo ponto-cerebelar (1/4); eram branco-acinzentados (4/5), avermelhados (1/5) e macios. Um caso foi descrito como placa (com $1,5 \mathrm{~cm}$ no seu maior eixo); era branco-acinzentado e macio.

\section{Achados histopatológicos}

Como informado anteriormente, quanto às características histológicas, os meningiomas foram classificados em: G-I (14 casos), G-II (3 casos) e G-III (5 casos), conforme o Quadro 1. Os subtipos histológicos incluídos como G-I (14/22) foram: psamomatoso (5/14) (Fig.1), meningotelial (3/14) (Fig.2), transicional (3/14) (Fig.3), microcístico (2/14) (Fig.4) e fibroblástico (1/14) (Fig.5). O subtipo psamomatoso foi identificado pelo predomínio de estruturas espirais, com o centro hialino lamelar ou mineralizado, denominadas corpos de psamoma (psamomma bodies). 0 estroma era escasso (3/5) e moderado (2/5). 0 subtipo meningotelial caracterizou-se pelo predomínio de células neoplásicas arranjadas em lóbulos de diferentes tamanhos (padrão sincicial). Em todos os casos o estroma era escasso e havia algumas células neoplásicas com pseudoinclusões intranucleares. 0 subtipo fibroblástico foi caracterizado pelo predomínio de células neoplásicas arranjadas em feixes direcionados paralelamente ou entrelaçados, em 


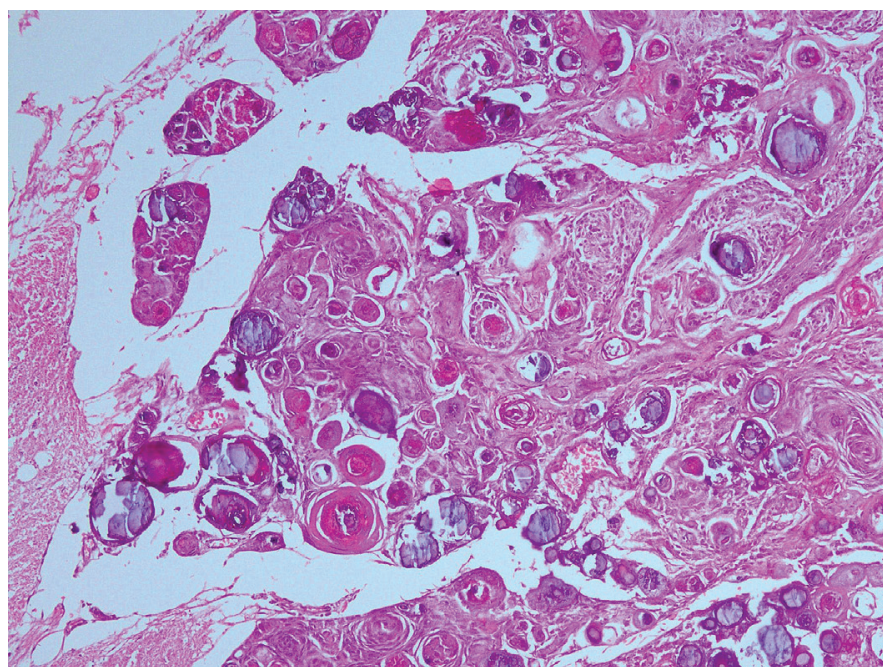

Fig.1. Meningioma psamomatoso, grau I, com múltiplos corpos de psamoma. HE, obj.10x.

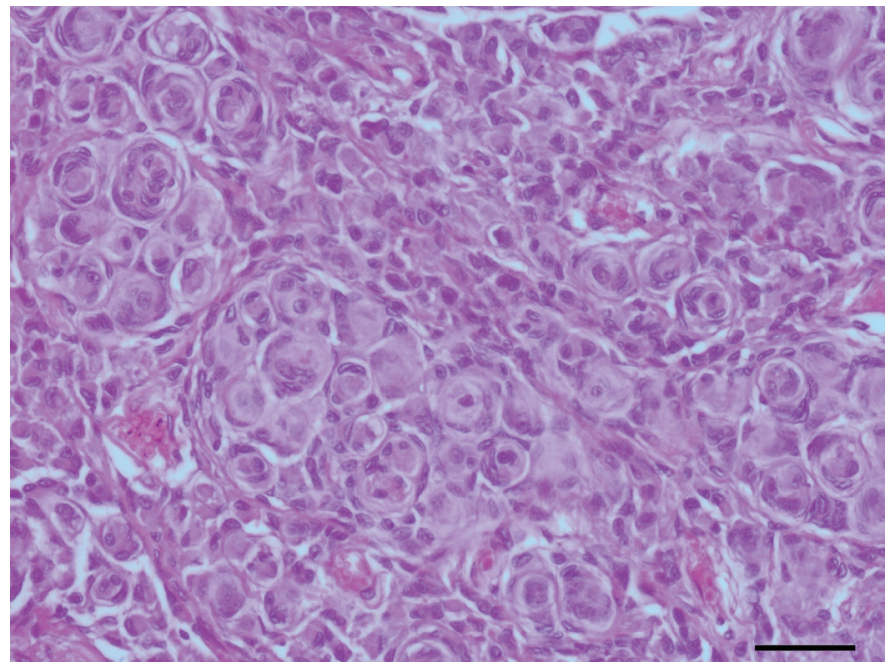

Fig.3. Meningioma transicional, grau I, há múltiplos espirais de células neoplásicas fusiformes. HE, obj.40x.

meio a uma matriz rica em fibras colágenas. Algumas áreas apresentavam hialinização de fibras colágenas.

O subtipo transicional foi caracterizado pela presença dos padrões meningotelial e fibroblástico em igual proporção, com frequentes redemoinhos (padrão misto). 0 estroma variou de moderado (2/3) a acentuado (1/3). Em dois casos, havia algumas pseudoinclusões intranucleares. 0 subtipo microcístico foi caracterizado pelo predomínio de células neoplásicas com formação de processos alongados e vacuolização citoplasmática e intersticial. $\mathrm{O}$ estroma era escasso nos dois casos.

Na maioria dos meningiomas G-I, pequenas áreas de proliferação de células neoplásicas com características de outros padrões foram observadas. Assim, em dois casos (2/14) havia áreas de padrão microcístico (casos 4 e 10). Foram observados três casos com $(3 / 14)$ áreas de padrão psamomatoso (casos 8, 10 e 11). Umas poucas áreas do

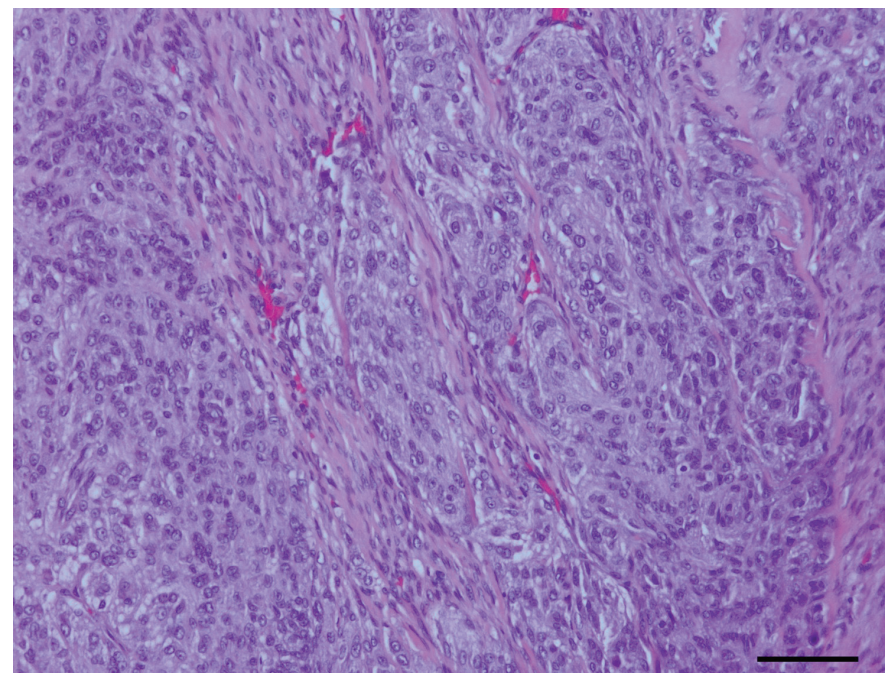

Fig.2. Meningioma meningotelial, grau I, com múltiplos lóbulos de células meningoteliais. HE, obj.20x.

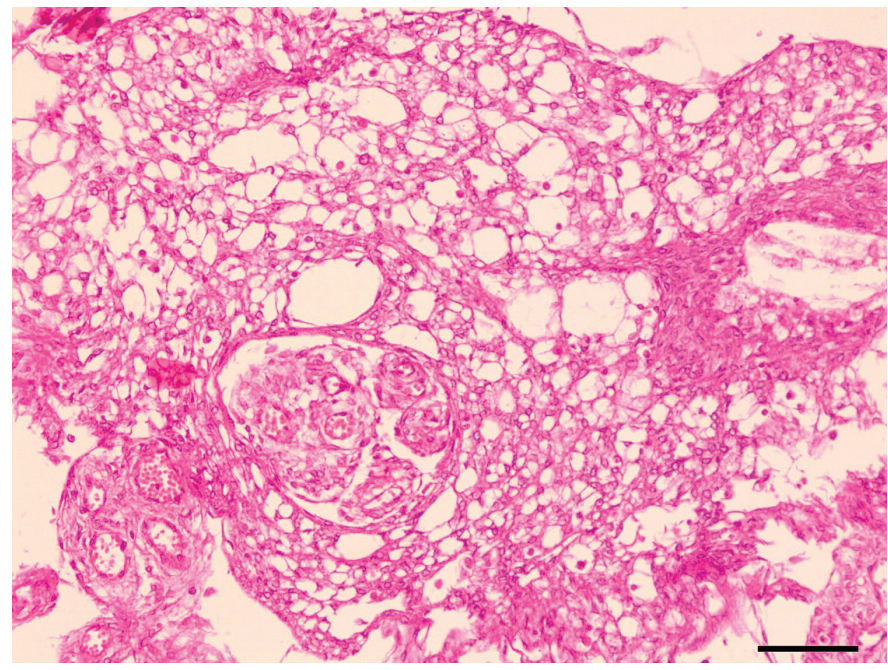

Fig.4. Meningioma microcístico, grau I, com múltiplas células vacuolizadas. HE, obj.20x.

subtipo fibroblástico (caso 10). No caso 9 se observaram algumas áreas do padrão papilar.

Nos meningiomas de G-I, atipia e pleomorfismo foram moderados em um caso (1/14). Em 5/14 casos (transicional - 2 casos, cães 9 e 10; meningotelial - 2 casos, cães 6 e 8; psamomatoso - 1 caso, cão 3) havia invasão local de ilhas sólidas de células neoplásicas no tecido nervoso peritumoral. Outros achados incluíram: necrose $(7 / 14)$, proliferação vascular peritumoral (4/14), edema peritumoral (4/14), hemorragia (2/14), degeneração walleriana medular espinhal (2/14), infiltrado inflamatório neutrofílico (1/14) e linfocítico (1/14).

Dos 22 meningiomas, três foram classificados como G-II (atípicos), sendo dois do subtipo cordoide e um do subtipo atípico. O subtipo cordoide (2/3) (Fig.6) foi caracterizado pela presença de células epitelioides 
neoplásicas arranjadas em cordões $(1 / 2)$ e trabéculas $(1 / 2)$ imersos em uma matriz basofílica mucoide. 0 subtipo atípico (Fig.7) foi caracterizado principalmente por ter 14 mitoses/10 campos de grande aumento (cga; 400x) e por células neoplásicas arranjadas em manto ou espirais, com alta celularidade, pleomorfismo e atipia acentuadas, células pequenas e estroma escasso. Há pequenas áreas do subtipo meningotelial nos três casos (casos 15 a 17). Observou-se a invasão de grupos sólidos de células neoplásicas no parênquima da medula espinhal (caso 17). Necrose multifocal (2/3), hemorragia (2/3) e proliferação vascular peritumoral $(1 / 3)$ foram observadas.

Dos 22 meningiomas, cinco foram classificados como malignos (G-III) e incluíram os subtipos papilar (4/5) e maligno (1/5). 0 subtipo papilar (Fig.8) foi identificado pela presença de células neoplásicas dispostas em camadas ao longo de

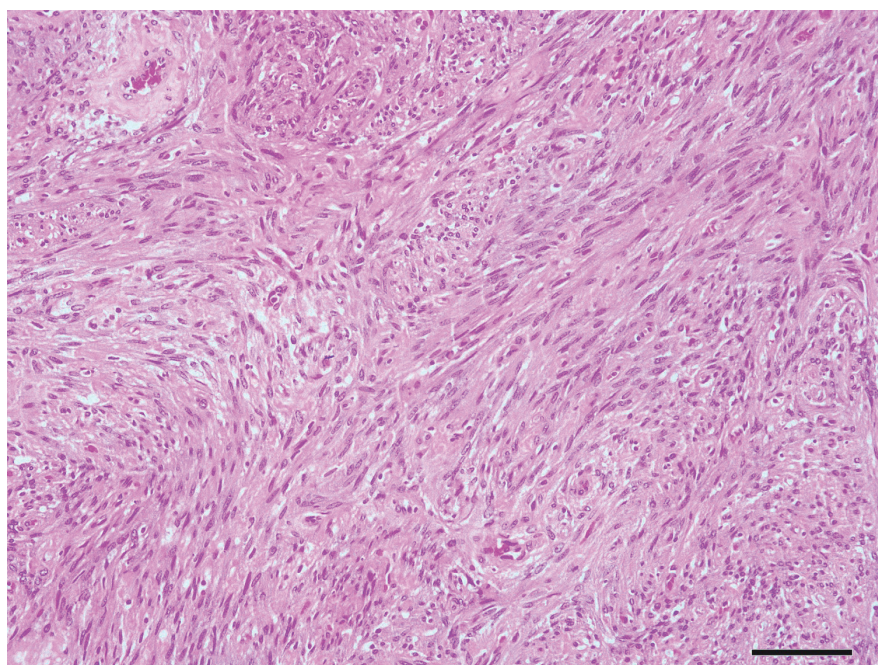

Fig.5. Meningioma fibroblástico, grau I, caracterizado por feixes intercalantes de células fusiformes. HE, obj.20x. eixos conjuntivo-vasculares, que lembram pseudo-rosetas perivasculares (pseudopapilíferas). Em um caso havia invasão vascular (Fig.9) na forma de grupos neoplásicos pseudopapilíferos. 0 subtipo maligno (Fig.10) foi caracterizado principalmente por ter 27 mitoses $/ 10$ cga e pela presença das células neoplásicas organizadas em lóbulos, alguns formando espirais, com alta celularidade, pleomorfismo e atipia nucleares acentuados e nucléolos proeminentes. 0 estroma era escasso. Em todos os casos de G-III foram observadas áreas de atipia e pleomorfismo celulares acentuados. Algumas áreas bem diferenciadas do padrão meningotelial foram observadas no caso 22 . Foi observada invasão cerebral em $4 / 5$ casos (cães 18 a 20 e 22). Necrose multifocal (3/5) ou coalescente (2/5), edema (2/5), hemorragia (1/5), proliferação vascular peritumoral $(1 / 5)$ e infiltrado neutrofílico $(1 / 5)$ foram também observados.

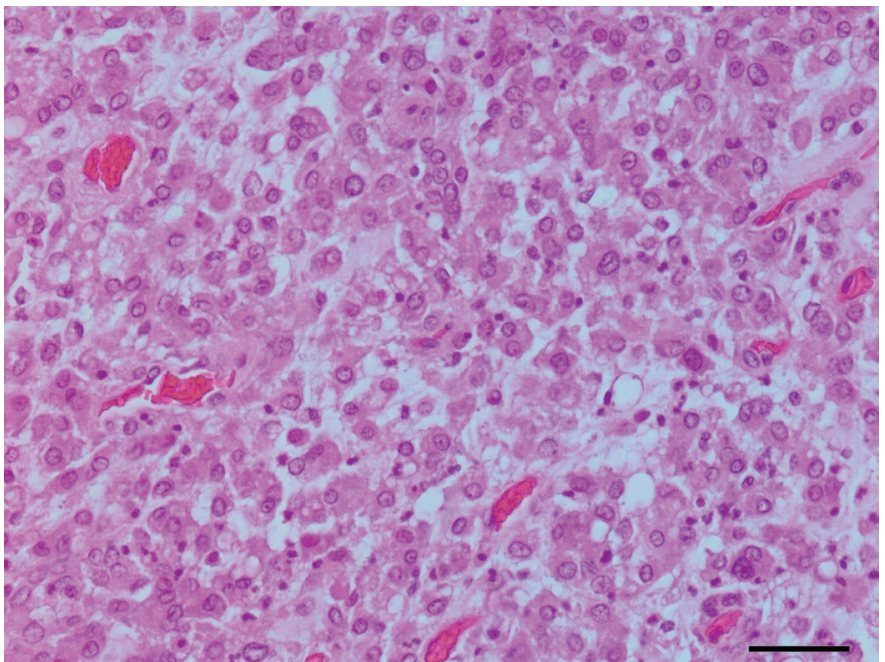

Fig.6. Meningioma cordoide, grau II, há cordões de células epitelioides imersos em uma matriz basofílica. HE, obj.40x.

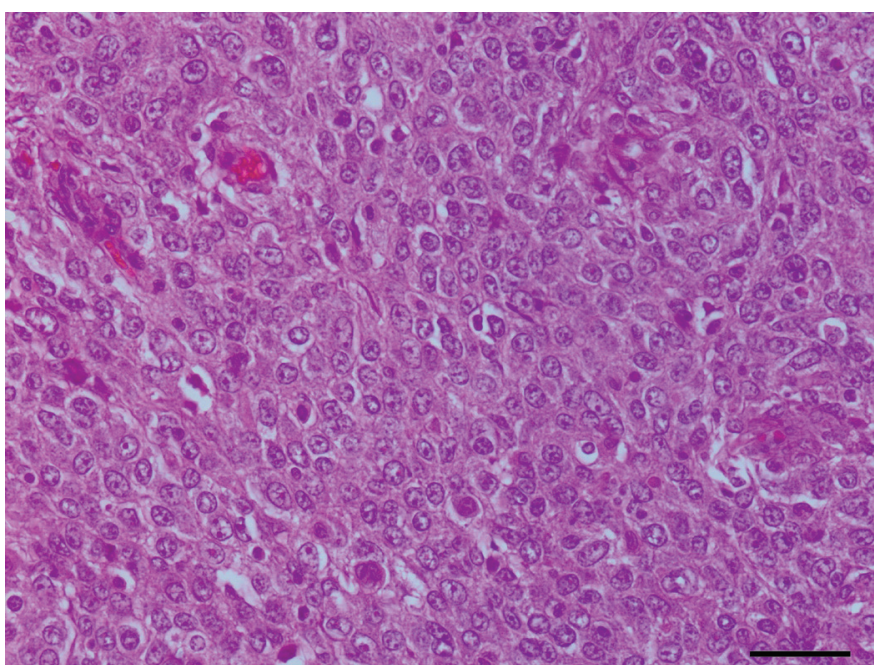

Fig.7. Meningioma atípico, grau II, com característica hipercelularidade de células pequenas e com arranjo em manto. HE, obj.40x.

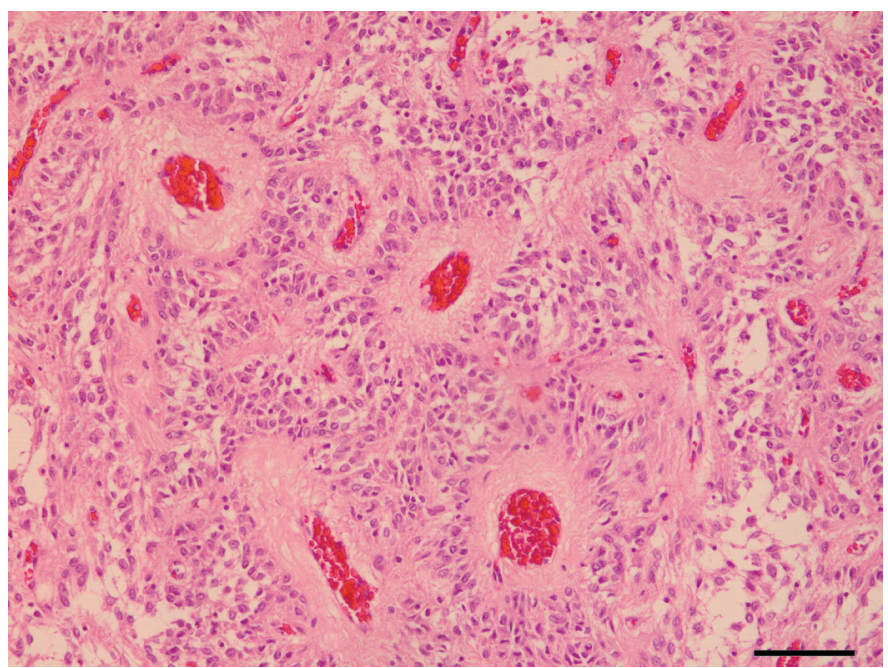

Fig.8. Meningioma papilar, grau III, apresentando arquitetura pseudopapilífera. HE, obj.20x. 


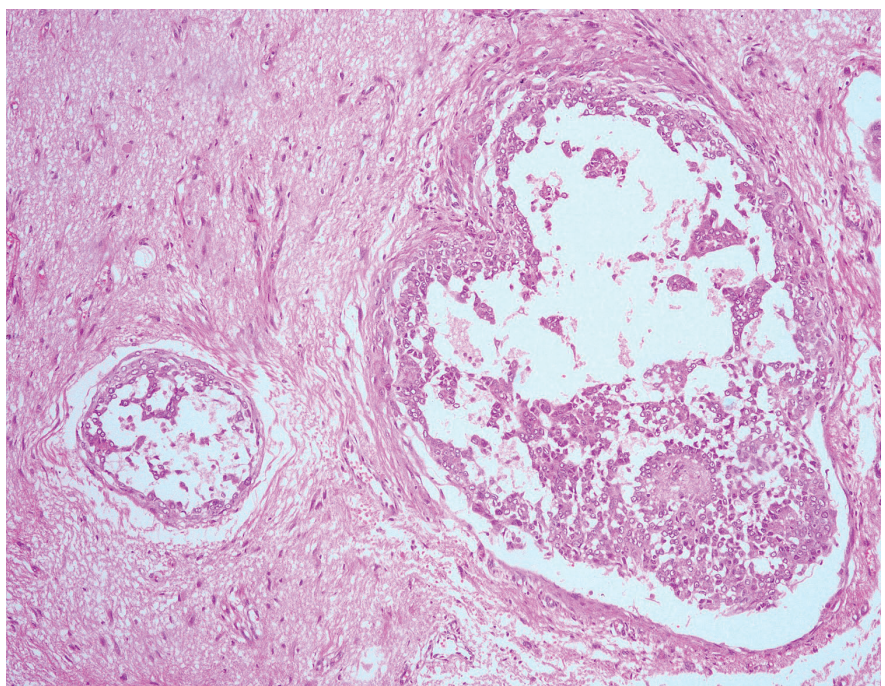

Fig.9. Meningioma papilar, grau III, êmbolos de células neoplásicas em vasos sanguíneos peritumorais. HE, obj.20x.

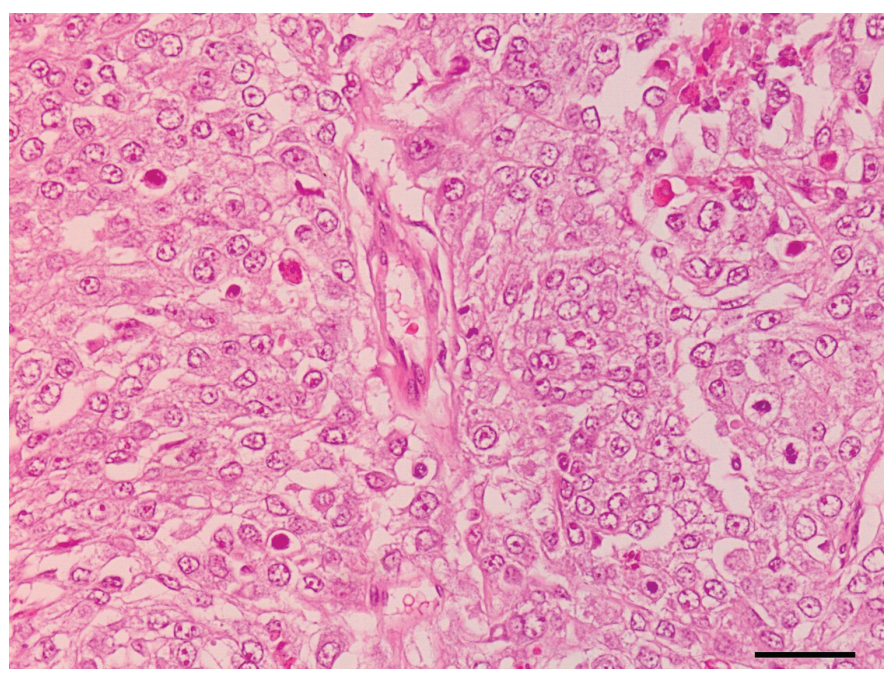

Fig.10. Meningioma maligno, grau III, células anaplásicas com numerosas figuras mitóticas. HE, obj.40x.

\section{DISCUSSÃo}

A graduação dos meningiomas varia consideravelmente de acordo com sua aparência histológica e taxa mitótica (Vandevelde et al. 2012). A aparência histológica é variada e depende principalmente da diferenciação epitelial ou mesenquimal e do arranjo do tumor (Summers et al. 1995). Neste estudo, os meningiomas G-I perfizeram $63,6 \%$ dos casos, os G-II, $13,6 \%$ e os G-III, 22,7\%. Isto diferiu da literatura internacional, em que a ordem decrescente de ocorrência geralmente é de G-I para G-III (Petersen et al. 2008, Sturges et al. 2008). Não foi possível estabelecer possíveis causas para essa diferença.

Quanto aos G-I, outros estudos foram relativamente semelhantes na frequência de ocorrência, perfazendo $53 \%$ dos casos (Petersen et al. 2008) ou 56\% (Sturges et al. 2008). 0 subtipo psamomatoso foi o mais frequente $(35,7 \%)$ dentre os G-I neste estudo, sendo considerado incomum (Montoliu et al. 2006, Sturges et al. 2008) ou nem relatado por outros autores (Patnaik et al. 1986, Barnhart et al. 2002, Petersen et al. 2008), sugerindo ser relativamente raro na literatura internacional. Na maioria dos estudos (Petersen et al. 2008, Sturges et al. 2008, José-López et al. 2013), os subtipos meningotelial e transicional são os mais comuns, sendo que neste trabalho cada um representou $21,4 \%$ dos G-I, ambos obtendo a segunda maior frequência nesse grau. 0 subtipo microcístico foi mencionado em livros textos referência em neuropatologia veterinária (Summers et al. 1995, Koestner \& Higgins 2002), mas não foi contemplado na classificação da OMS de 1999 para animais domésticos (Koestner et al. 1999). Posteriormente, este subtipo foi abordado por Montoliu et al. (2006) de forma independente. Foi diagnosticado um caso do subtipo fibroblástico $(7,1 \%)$, sendo também reportado em outros estudos como incomum (Patnaik et al. 1986, Barnhart et al. 2002, Montoliu et al. 2006).

Além disso, é comum se observar dois ou mais diferentes padrões morfológicos no mesmo tumor, por isso a classificação do subtipo histológico dos meningiomas é baseada no padrão predominante (Patnaik et al. 1986, Summers et al. 1995). Neste estudo, aproximadamente 28,5\% tinham arranjo de dois subtipos, enquanto cerca de $7,1 \%$ tinham quatro subtipos no mesmo tumor. No caso 9, cujo padrão predominante era o transicional, observou-se aproximadamente $20 \%$ do tumor com padrão papilar. Por mais que o arranjo papilar seja de alto grau (G-III), segundo a OMS de 2007, este subtipo tem que representar mais de $50 \%$ do tumor para considerar-se nessa graduação (Mawrin \& Perry 2010, Lopes \& Vandenberg 2013). Nesses casos, alguns autores adicionam no diagnóstico de meningiomas humanos a variante (por exemplo, meningioma transicional com padrão papilar focal) (Mawrin \& Perry 2010).

Algumas "peculiaridades" dos meningiomas classificados como G-I (benignos) merecem ser discutidas. Na metade dos casos observaram-se grandes áreas de necrose na região central do tumor. Em neoplasmas em geral, estas são atribuíveis à isquemia devido à perfusão inadequada através da vasculatura anormalmente permeável ou ao aumento da pressão no centro da massa, a qual restringe a perfusão de vasos de pequeno calibre (Cullen et al. 2002). Em um caso foram observadas áreas de atipia nuclear. Vale salientar que "atipias nucleares" não são confiáveis para determinar um grau mais elevado ao tumor (G-II, por exemplo), pois meningiomas G-I podem mostrar graus consideráveis de atipias nucleares "degenerativas", semelhantes às observadas nos G-II subtipo atípico em humanos, em que a "atipia nuclear" não tem uma correspondência com um comportamento clínico subsequente (Mawrin \& Perry 2010).

A invasão do tecido nervoso, como observada neste estudo (35,7\% dos G-I, 33,3\% dos G-II e 80\% dos G-III), já foi relatada em meningiomas G-I e G-II (atípicos) em cães (Sturges et al. 2008). A questão da "invasão do tecido nervoso" observada em alguns meningiomas histologicamente classificados como benignos merece alguns esclarecimentos. Pela classificação dos meningiomas em humanos da OMS de 2007 (Louis et al. 2007), a invasão encefálica não está incluída entre os critérios histológicos para a classificação dos mengiomas grau II (atípicos), permitindo que meningiomas de grau I (benignos) possam apresentar essa característica, sem que isso altere sua graduação para graus mais elevados. Entretanto, em alguns estudos observou-se que a invasão cerebral em tumores grau I implicou estatisticamente em taxas de recidiva e mortalidade 
semelhantes às dos G-II. Portanto, para alguns autores, do ponto de vista prognóstico, meningiomas de humanos que invadem o cérebro, mesmo se histologicamente benignos (G-I), deveriam ser considerados como um G-II da OMS (Mawrin \& Perry 2010, Lopes \& Vandenberg 2013). Em um estudo publicado em 2014, verificou-se que a frequência de invasão do SNC peritumoral em humanos aumentou com o grau do meningioma, sendo de $28 \%$ para os G-I, $64 \%$ para G-II e 100\% para G-III (Pizem et al. 2014). Recentemente, um artigo resumindo as mudanças na nova classificação de meningiomas em humanos da OMS de 2016 (Louis et al. 2016), mostra que a invasão cerebral passou a constar como critério de classificação de meningiomas atípicos (no G-II). Já tem sido sugerido incluir esse critério para atribuir um G-II em meningiomas de cães (Mandara et al. 2010), porém isso ainda não foi adotado em medicina veterinária.

Os meningiomas G-II representaram 13,6\%, em contraste com estudos em que sua frequência atingiu $43 \%$ (Sturges et al. 2008) e 44\% (Petersen et al. 2008). Não foi possível estabelecer possíveis razões para essa diferença na prevalência. Chamou a atenção a maior frequência do subtipo cordoide em relação ao atípico, o que foi incomum na literatura consultada (Sturges et al. 2008, Petersen et al. 2008, Mandara et al. 2010). À medida que os meningiomas se tornam menos diferenciados (G-II), passam a apresentar três ou mais dos seguintes critérios como: arranjo em manto, células pequenas, atipia, aumento da celularidade e áreas de necrose (Sturges et al. 2008, Mawrin \& Perry 2010, Vandevelde et al. 2012). No único caso do subtipo atípico, foram observados quatro de cinco critérios de morfologia, além do índice mitótico elevado (o critério é $>4$ a 19 mitoses/10cga). Em humanos, aproximadamente $75 \%$ dos meningiomas G-II são classificados em virtude de seu índice mitótico (Barresi et al. 2016).

Para o subtipo cordoide, os critérios morfológicos descritos acima para o G-II (subtipo atípico) não se aplicam, pois só o padrão já representa um pior prognóstico (Vandevelde et al. 2012), tendo aqui uma baixa frequência (2/22), semelhante a um estudo anterior (Sturges et al. 2008). Este subtipo tem sido considerado com base em publicações e livros de referência mais recentes (Sturges et al. 2008, Vandevelde et al. 2012, Cantile \& Youssef 2016). Anteriormente, era denominado variante mixoide (Van Winkle et al.1994), porém passou a ser chamado cordoide pelos neuropatologistas americanos pela semelhança com a variante cordoide descrita em humanos (AFIP 2008). Invasão ao parênquima foi observada nos dois casos aqui descritos, semelhantemente a outro estudo (Sturges et al. 2008).

Neste estudo, foi observada uma alta frequência $(22,7 \%)$ de meningiomas de G-III comparado a maioria dos estudos internacionais em que os G-III perfizeram 1\% (Sturges et al. 2008) e 3\% (Petersen et al. 2008). Isso foi consequência da alta frequência $(18,2 \% ; 4 / 22)$ do subtipo papilar aqui observada. Os meningiomas papilares são reportados esporadicamente na literatura veterinária (Koestner et al. 1999, Montoliu et al. 2006), e em outros estudos retrospectivos eles não foram observados (Petersen et al. 2008, Sturges et al. 2008). Em um estudo na Itália (Mandara et al. 2015), houve também uma alta frequência de meningiomas papilares (15,7\%). Dos quatro casos de meningioma papilar, um deles apresentou critérios de malignidade como invasão intravascular que foi semelhante aos meningiomas papilares em humanos. Segundo a OMS, a taxa de metástase extracraniana de meningiomas papilares em humanos é relatada em 20\% dos casos (Lopes \& Vandenberg 2013).

Segundo uma revisão (Motta et al. 2012), a ocorrência de metástases de meningiomas é rara em animais domésticos e tem sido sugerido que as metástases de meningiomas são infrequentes devido à presença de intercomunicações desmossomais e interdigitações entre as células das meninges, o que reduz a esfoliação celular. As metástases ocorreriam por via hematógena ou pelo líquor (Long 2006). A malignidade dos meningiomas G-III em cães não está apenas associada à sua capacidade de metastatizar para fora do SNC (Vandevelde et al. 2012), embora isso possa ocorrer eventualmente (Geib 1966, Schulman et al. 1992, Pérez et al. 2005). Ela está também associada a fatores que incluem alta taxa mitótica e características citológicas malignas, para o subtipo maligno (Cantile \& Youssef 2016), e alta taxa de recidiva pós-cirúrgica e um baixo tempo de sobrevivência, para o subtipo papilar (Mandara et al. 2015).

Apesar de existirem poucos trabalhos que apresentem a graduação de meningiomas de cães, a maioria concorda que o subtipo maligno é incomum (Petersen et al. 2008, Sturges et al. 2008). Neste estudo, o principal critério de classificação do subtipo maligno foi a alta taxa mitótica (27/10cga; o critério é $>20 / 10$ cga). Em geral, esse subtipo pode ter morfologia acentuadamente anaplásica ou indiferenciada, afastando-se da morfologia meningotelial e aproximando-se dos sarcomas, carcinomas ou melanomas (Vandevelde et al. 2012, Cantile \& Youssef 2016). No caso estudado, havia áreas pouco diferenciadas, porém havia áreas menores e focais de diferenciação meningotelial, assegurando o diagnóstico histológico de meningioma. Para meningiomas é reconhecido que o diagnóstico definitivo mais confiável é feito através exame histopatológico (Sturges et al. 2008, Motta et al. 2012).

De acordo com a literatura (Patnaik et al. 1986, Montoliu etal. 2006, Sturges et al. 2008, Vandevelde et al. 2012, Cantile \& Youssef 2016) não há predisposição por sexo em cães. Em contraste, em humanos há maior predisposição em mulheres, talvez associada a receptores esteroidais intratumorais. Nas mulheres, a grande maioria dos meningiomas são de G-I. Entretanto, meningiomas com alta graduação são mais frequentes em homens (Lopes \& Vandenberg 2013). No estudo de Mandara et al. (2015), meningiomas papilares (G-III) foram mais observados em cães machos $(10 / 16)$. Neste estudo, a ocorrência de meningiomas foi maior em cadelas (relação macho:fêmea de 1:2,7), semelhante ao observado por outros autores (Petersen et al. 2008, Costa 2009), sendo as fêmeas mais representadas nos de G-I (10/14), as únicas acometidas no G-II e perfizeram 3/5 no G-III.

De forma geral, como ocorre para a maioria das neoplasias, independente da origem, cães mais velhos foram os mais acometidos nos 22 casos analisados, em que 50,4\% (12/22) tinham 10 anos ou mais, não diferindo de estudos anteriores (Patnaik et al. 1986, Snyder et al. 2006, Sturges et al. 2008, Costa 2009). Em humanos o subtipo papilar (G-III) é mais frequente em jovens (Lopes \& Vandenberg 2013). Entretanto, num estudo de 16 cães com meningioma papilar, a média de idade foi 10 anos (cães idosos) (Mandara et al. 2015). Neste estudo, a média de idade para cães com este subtipo (e grau) foi de 8 anos (cães adultos). Para os G-I e G-II, as médias de idade foram 11 e 12 anos, respectivamente. 
Meningiomas em cães são descritos comumente no Pastor Alemão (Patnaik et al. 1986, Montoliu et al. 2006, Sturges et al. 2008), Boxer (Montoliu et al. 2006, Petersen et al. 2008, Sturges et al. 2008, Vandevelde et al. 2012), Golden Retriever (Petersen et al. 2008, Sturges et al. 2008, Vandevelde et al. 2012), Labrador (Petersen et al. 2008, Sturges et al. 2008), Poodle (Marcasso et al. 2015), Collie (Petersen et al. 2008) e Terriers (Song et al. 2013). Neste estudo, cães de raça foram os mais acometidos, sendo que a raça Boxer $(31,8 \%)$ foi a mais representada, seguida pelo Pastor Alemão $(18,1 \%)$. É válido salientar que na população de raças de cães necropsiados no LPV-UFSM entre 1994 e 2003, as raças Pastor Alemão e Boxer ocuparam o primeiro e terceiro lugares em prevalência, respectivamente, e entre 2004 e 2013 elas ocuparam o terceiro e sexto lugares, respectivamente (Flores 2016). Apesar do número de casos analisados ser limitado, chama a atenção que de cinco casos classificados como G-III, quatro eram cães Boxer.

Por tratar-se de um sistema de classificação de meningiomas caninos adaptado de humanos, com um número ainda restrito de publicações (Petersen et al. 2008, Sturges et al. 2008, José-López et al. 2013, Mandara et al. 2015), a discussão sobre a relação entre os graus histológicos e a evolução clínica ainda permanece limitada, pois ainda não há parâmetros bem estabelecidos para o tempo médio de sobrevivência dos cães após o início dos sinais clínicos em cada grau da classificação histológica. Para humanos, há uma relação bem estabelecida neste sistema de graduação, a qual é baseada no tempo de sobrevivência pós-cirurgia e radioterapia (por exemplo, o tempo livre de recidiva de 10 anos foi de $95 \%$ para os G-I, de $56 \%$ para os G-II e inexistente para os G-III, os quais não sobreviveram a esse período) (Pizem et al. 2014). Entretanto, os dados obtidos neste estudo servem como parâmetros comparativos para estudos futuros de meningiomas em cães graduados por este sistema. Os cães com meningiomas G-I tiveram o maior tempo de sobrevivência (máximo de um ano) após a manifestação dos sinais clínicos $(8 / 14$ receberam tratamento clínico, incluindo corticoides e anticonvulsivantes). Dos G-III, o tempo máximo de sobrevivência foi de 90 dias, sendo que 2/5 receberam tratamento clínico e dos G-II, o tempo máximo foi de 20 dias, sendo que $2 / 3$ receberam tratamento. Não foi possível estabelecer os fatores que influenciaram na maior sobrevivência dos cães com meningiomas G-III em relação aos G-II aqui estudados, ou a influência do tratamento nessa evolução clínica. Nenhum dos cães deste estudo foi submetido a tratamento cirúrgico.

Ainda assim, algumas comparações podem ser feitas com alguns subtipos específicos. Há um estudo de oito cães com meningiomas G-III (subtipo papilar) em que os animais apenas receberam terapias de suporte e a evolução clínica variou de 1 a 90 dias (Mandara et al. 2015). Neste estudo, quatro cães com meningiomas papilares, dois que receberam e dois que não receberam tratamento, tiveram uma evolução clínica de 30 a 90 dias. Nos dois casos aqui descritos de meningiomas G-I intraespinhais, sem tratamento cirúrgico, a evolução dos sinais clínicos variou de 60 a 120 dias, sendo que, com tratamento cirúrgico, meningiomas G-I tiveram evolução de 110 a 600 dias. 0 único meningioma G-II intraespinhal (subtipo atípico) deste estudo teve evolução clínica de sete dias. Casos de neoplasmas semelhantes tratados cirurgicamente tiveram evolução de 300 a 540 dias (José-López et al. 2013).
A localização anatômica dos meningiomas determina a sua denominação, tais como, meningiomas intracranianos, intraespinhais, retro-bulbares e paranasais (Koestner \& Higgins 2002, Vandevelde et al. 2012). A localização dos meningiomas intracranianos foi mais prevalente na região supratentorial como as regiões olfatória, parassagital, convexidade do cérebro e parasselar, semelhante a outros estudos (Patnaik et al. 1986, Summers et al. 1995, Koestner \& Higgins 2002, Snyder et al. 2006, Sturges et al. 2008), que sugerem uma correlação direta com a densidade dos vilos da aracnoide nessas áreas, como descrito em humanos (Vandevelde et al. 2012). Em um estudo de 112 casos de meningiomas em cães, não foi observada relação do grau histológico com a localização intracraniana (Sturges et al. 2008). Em contraste, os meningiomas G-II e G-III em humanos ocorrem em baixa frequência na base do crânio (Sade et al. 2007). Neste estudo, a localização parasselar foi observada em um caso de G-II e em um caso de G-III. Em outro caso de G-III a localização foi na região olfatória. Em outros estudos, apesar de não ter sido discutido o assunto, foi observada uma baixa frequência de G-II e G-III na base do crânio em cães (Mandara et al. 2010, Rissi 2015).

A localização dos três meningiomas intraespinhais neste estudo ficou restrita entre as regiões de $\mathrm{C} 1$ a $\mathrm{T} 2$ e eram intradurais/extramedulares. Em outros estudos foi observada uma relação de maior frequência de meningiomas G-I no segmento C1-C4 e os G-II eram predominantes mais caudalmente (Petersen et al. 2008, Vandevelde et al. 2012). A maioria dos meningiomas intraespinais humanos ocorre na região torácica. A razão dessa predileção ainda não foi estabelecida, mas em humanos as células da membrana aracnoide (encontradas dentro de proliferações aracnoides) poderiam ser as células progenitoras para os meningiomas e outros tipos de proliferações aracnoides, sendo mais comuns na coluna torácica. A distribuição das proliferações aracnoides nas meninges espinhais em cães é desconhecida (Petersen et al. 2008).

Os sinais neurológicos decorrentes de tumores no SNC dependem do tamanho, da localização e da taxa de crescimento tumoral (Costa 2009). Devido a sua cronicidade, as neoplasias causam sinais neurológicos progressivos (Summers et al. 1995). Com relação à localização intracraniana, os sinais de alteração tálamo-cortical (65\%) foram os mais frequentes, como previamente observado (Costa 2009, Marcasso et al. 2015), e foram caracterizados principalmente por convulsão (76,9\%). Crise convulsiva é a manifestação neurológica mais frequente em cães com neoplasmas encefálicos de qualquer origem (Bagley \& Gavin 1998, Snyder et al. 2006, Costa 2009). Os meningiomas intraespinhais causaram com maior frequência sinais de ataxia proprioceptiva, déficit de propriocepção e paresia/paraplegia. Independentemente do segmento medular afetado, a localização e a extensão da lesão é que determinarão a dificuldade locomotora do animal, podendo variar de monoparesia a tetraplegia (Santos et al. 2012, Costa 2009, Marcasso et al. 2015).

\section{CONCLUSÕES}

Este estudo permitiu estabelecer uma relação entre os três graus histológicos observados em 22 casos de meningiomas em cães com vários parâmetros clínico-epidemiológicos e patológicos, fornecendo informações úteis para um melhor 
conhecimento da correlação entre a graduação histológica e a evolução clínica desses neoplasmas.

Dentre as principais relações estabelecidas, observou-se que os meningiomas intracranianos e de localização supratentorial foram os mais frequentes; os intracranianos caracterizaram-se principalmente por sinais clínicos de alteração tálamo-cortical; os intraespinhais caracterizaram-se principalmente por causarem ataxia.

Quanto aos meningiomas G-I, o subtipo psamomatoso foi o mais frequente; fêmeas foram mais acometidas $(71,4 \%)$; a média de idade foi de 11 anos; e um maior tempo de sobrevivência (máximo de um ano) após a manifestação dos sinais clínicos foi observado.

Os G-II tiveram o subtipo cordoide como o mais frequente; somente fêmeas acometidas; a média de idade de 12 anos; e o tempo máximo de sobrevivência de 20 dias.

Os G-III tiveram o subtipo papilar como o mais frequente; um maior número de fêmeas acometidas (60\%); uma média de idade de 8 anos; $80 \%$ dos cães acometidos da raça Boxer; e o tempo máximo de sobrevivência de 90 dias.

\section{REFERÊNCIAS}

Afip 2008. Armed Forces Institute of Pathology. Proceedings of the Wednesday Slide Conference, Silver Spring, MD. Disponível em <http://www.askjpc. org/wsco/wsc_showcase2.php?id=192> Acesso em 14 abr. 2015.

Bagley R.S. \& Gavin P.R. 1998. Seizures as a complication of brain tumors in dogs. Clin. Tech. Small Anim. Pract. 13(3):179-184. http://dx.doi. org/10.1016/S1096-2867(98)80039-X. PMid:9775508.

Barnhart K.F., Wojcieszyn J. \& Storts R.W. 2002. Immunohistochemical staining patterns of canine meningiomas and correlation with published immunophenotypes. Vet. Pathol. 39(3):311-321. http://dx.doi.org/10.1354/ vp.39-3-311. PMid:12014495.

Barresi V., Caffo M. \& Tuccari G. 2016. Classification of human meningiomas: lights, shadows, and future perspectives. J. Neurosci. Res. 94(12):16041612. http://dx.doi.org/10.1002/jnr.23801. PMid:27376782.

Cantile C. \& Youssef S. 2016. Nervous system, p.251-406. In: Maxie M.G. (Ed.), Jubb, Kennedy and Palmer's Pathology of Domestic Animals. Vol.1. 6th ed. Saunders Elsevier, Philadelphia. 797p. http://dx.doi.org/10.1016/ B978-0-7020-5317-7.00004-7.

Costa R.C. 2009. Neoplasias do sistema nervoso, p.412-427. In: Daleck R.C., De Nardi A.B. \& Rodaski S. (Eds), Oncologia em Cães e Gatos. Roca, São Paulo. 612p.

Cullen J.M., Page R. \& Misdorp W. 2002. An overview of cancer, pathogenesis, diagnosis, and management, p.3-44. In: Meuten D.J. (Ed.), Tumors in Domestic Animals. 4th ed. Iowa State Press, Iowa. 788p. http://dx.doi. org/10.1002/9780470376928.ch1.

Fighera R.A., Souza T.M., Silva M.C., Brum J.S., Graça D.L., Kommers G.D., Irigoyen L.F. \& Barros C.S.L. 2008. Causas de morte e razões para eutanásia de cães. Pesq. Vet. Bras. 28(4):223-230. http://dx.doi.org/10.1590/S0100736X2008000400005.

Flores M.M. 2016. Aspectos epidemiológicos do câncer em cães da região central do rio grande do sul: 50 anos (1964-2013). Tese de Doutorado em Medicina Veterinária, Universidade Federal de Santa Maria, Santa Maria, RS. 90p.

Geib L.W.1966. Ossifying meningioma with extracranial metastasis in a dog. Pathol Vet. 3(3):247-254. PMid:6006232.

José-López R., De la Fuente C., Pumarola M. \& Anor S. 2013. Spinal meningiomas in dogs: description of 8 cases including a novel radiological and histopathological presentation. Can. Vet. J. 54(10):948-954. PMid:24155414.
Josephson G.K.A. \& Little P.B. 1990. Four bovine meningeal tumors. Can. Vet. J. 31(10):700-703. PMid:17423678.

Koestner A. \& Higgins R. 2002. Tumors of the nervous system, p.697-738. In: Meuten D.J. (Ed.), Tumors in Domestic Animals. 4th ed. Iowa State Press, Iowa. 788p.

Koestner A., Bilzer T., Fatzer R., Schulmer F.Y.S., Summer B.A. \& Van Winkle T.J. 1999. Histological classification of the tumors of the nervous system of domestic animals. p.25-26. In: Koestner A., Bilzer T., Fatzer R., Schulmer F.Y.S., Summer B.A. \& Van Winkle T.J. (Eds), International Histological Classification of the Tumors of Domestic Animals. 2nd Series, Vol.5. Armed Forces Institute of Pathology, Washington, D.C.

Kreeger J.M., Templer A., Tumquist S.E., Bailey K.L., Johnson P.J. \& Wilson D.A. 2002. Paranasal meningioma in a horse. J. Vet. Diagn. Invest. 14(4):322325. http://dx.doi.org/10.1177/104063870201400408. PMid:12152812.

Long S. 2006. Neoplasia of the Nervous System. Disponível em <http:// www.ivis.org/advances/Vite/braund26/chapter. asp?LA=1> Accesso em 14 abr. 2015

Lopes M.B.S. \& Vandenberg S.R. 2013. Tumor of the central nervous system, p.1933-2031. In: Fletcher C.D.M. (Ed.), Diagnostic Histopathology of Tumors. Vol.2. 4th ed. Saunders Elsevier, Philadelphia. 2145p.

Louis D.N., Ohgaki H., Wiestler O.D., Cavenee W.K., Burger P.C., Jouvet A., Scheithauer B.W. \& Kleihues P. 2007. The WHO classification of tumours of the central nervous system. Acta Neuropathol. 114(2):97-109. http:// dx.doi.org/10.1007/s00401-007-0243-4. PMid:17618441.

Louis D.N., Perry A., Reifenberger G., von Deimling A., Figarella-Branger D., Cavenee W.K., Ohgaki H., Wiestler O.D., Kleihues P. \& Ellison D.W. 2016. The 2016 world health organization classification of tumors of the central nervous system: a summary. Acta Neuropathol. 131(6):803-820. http:// dx.doi.org/10.1007/s00401-016-1545-1. PMid:27157931.

Mandara M.T., Pavone S., Brunetti B. \& Mandrioli L. 2010. A comparative study of canine and feline meningioma classification based on the WHO histological classification system in humans. Proc. 22nd Symposium ESVN-ECVN, Bologna, 24-26 September 2009. J. Vet. Intern. Med. 24:235-258.

Mandara M.T., Reginato A., Foiani G., Baroni M., Poli F., Gasparinetti N. \& Bernardini M. 2015. Papillary meningioma in the dog: a clinicopathological case series study. Res. Vet. Sci. 100:213-219. http://dx.doi.org/10.1016/j. rvsc.2015.03.029. PMid:25847284.

Marcasso R.A., Moreira J.R., Valentim L.G., Arias M.V.B. \& Bracarense A.P.F.R.L. 2015. Meningiomas em cães: aspectos clínicos, histopatológicos e imunohistoquímicos. Pesq. Vet. Bras. 35(10):844-852. http://dx.doi.org/10.1590/ S0100-736X2015001000005.

Mawrin C. \& Perry A. 2010. Pathological classification and molecular genetics of meningiomas. J. Neurooncol. 99(3):379-391. http://dx.doi.org/10.1007/ s11060-010-0342-2. PMid:20809251.

Montoliu P., Anor S., Vidal E. \& Pumarola M. 2006. Histological and immunohistochemical study of 30 cases of canine meningioma. J. Comp. Pathol. 135(4):200-207. http://dx.doi.org/10.1016/j.jcpa.2006.06.006. PMid:17049358.

Motta L., Mandara M.T. \& Skerritt G.C. 2012. Canine and feline intracranial meningiomas: an updated review. Vet J. 192(2):153-165. http://dx.doi. org/10.1016/j.tvjl.2011.10.008. PMid:22104505.

Patnaik A.K., Kay W.J. \& Hurvitz A.I. 1986. Intracranial meningioma: a comparative pathologic study of 28 dogs. Vet. Pathol. 23(4):369-373. http:// dx.doi.org/10.1177/030098588602300404. PMid:3750730.

Pérez V., Vidal E., González N., Benavides J., Ferreras M.C., Villagrasa M. \& Pumarola M. 2005. Orbital meningioma with a granular cell component in a dog, with extracranial metastasis. J. Comp. Pathol. 133(2-3):212-217. http://dx.doi.org/10.1016/j.jcpa.2005.02.003. PMid:16045918.

Petersen S.A., Sturges B.K., Dickinson P.J., Pollard R.E., Kass P.H., Kent M., Vernau K.M., Lecouteur R.A. \& Higgins R.J. 2008. Canine intraspinal meningiomas: imaging features, histopathologic classification, and long- 
term outcome in 34 dogs. J. Vet. Intern. Med. 22(4):946-953. http://dx.doi. org/10.1111/j.1939-1676.2008.0106.x. PMid:18482277.

Pizem J., Velnar T., Prestor B., Mlakar J. \& Popovic M. 2014. Brain invasion assessability in meningiomas is related to meningioma size and grade, and can be improved by extensive sampling of the surgically removed meningioma specimen. Clin. Neuropathol.33(5):354-363. http://dx.doi. org/10.5414/NP300750. PMid:25034703.

Rissi D.R. 2015. A retrospective study of skull base neoplasia in 42 dogs. J. Vet. Diagn. Invest. 27(6):743-748. http://dx.doi.org/10.1177/1040638715611706. PMid:26462763.

Sade B., Chahlavi A., Krishnaney A., Nagel S., Choi E. \& Lee J.H. 2007. World Health Organization Grades II and III meningiomas are rare in the cranial base and spine. Neurosurgery 61(6):1194-1198, discussion 1198. http:// dx.doi.org/10.1227/01.neu.0000306097.38141.65. PMid:18162898.

Santos R.P., Fighera R.A., Beckmann D.V., Brum J.S., Ripplinger A., Neto D.P., Baumhardt R. \& Mazzanti A. 2012. Neoplasmas envolvendo o sistema nervoso central de cães: 26 casos (2003-2011). Pesq. Vet. Bras. 32(2):153158. http://dx.doi.org/10.1590/S0100-736X2012000200011.

Schulman F.Y., Ribas J.L., Carpenter J.L., Sisson A.F. \& LeCouteur R.A. 1992. Intracranial meningioma with pulmonary metastasis in three dogs. Vet. Pathol. 29(3):196-202. http://dx.doi.org/10.1177/030098589202900302. PMid:1621330.

Snyder J.M., Shofer F.S., Van Winkle T.J. \& Massicotte C. 2006. Canine intracranial primary neoplasia: 173 cases (1986-2003). J. Vet. Intern. Med. 20(3):669675. PMid:16734106.
Song R.B., Vite C.H., Bradley C.W. \& Cross J.R. 2013. Postmortem evaluation of 435 cases of intracranial neoplasia in dogs and relationship of neoplasm with breed, age, and body weight. J. Vet. Intern. Med. 27(5):1143-1152. http://dx.doi.org/10.1111/jvim.12136. PMid:23865437.

Sturges B.K., Dickinson P.J., Bollen P.D., Koblik P.H., Kass G.D., Kortz K.M., Vernau M.F., Knipe R.A., Lecouteur R.A. \& Higgins R.J. 2008. Magnetic resonance imaging and histological classification of intracranial meningiomas in 112 dogs. J. Vet. Intern. Med. 22(3):586-595. http://dx.doi.org/10.1111/j.19391676.2008.00042.x. PMid:18466258.

Summers B.A., Cummings J.F. \& De Lahunta A. 1995. Tumors of the central nervous system, p.351-401. In: Summers B.A., Cummings J.F. \&. De Lahunta A. (Eds), Veterinary Neuropathology. Mosby, Missouri.

Troxel M.T., Vite C.H., Massicotte C., McLear R.C., Winkle T.J.V., Glass E.N., Tiches D. \& Dayrell-Hart B. 2004. Magnetic resonance imaging features of feline intracranial neoplasia: retrospective analysis of 46 cats. J. Vet. Intern. Med.18(2):176-189. http://dx.doi.org/10.1111/j.1939-1676.2004. tb00158.x. PMid:15058768.

Van Winkle T.J., Steinberg H.S., DeCarlo A.J., Dayrell-Hart B., Steinberg S.A., Smith C.A. \& Summers B.A. 1994. Myxoid meningiomas of the Rostral Cervical Spinal Cord and Caudal Fossa in four dogs. Vet. Pathol. 31(4):468471.http://dx.doi.org/10.1177/030098589403100410. PMid:7941237.

Vandevelde R., Higgins R.J. \& Oevermannn A. 2012. Neoplasia. p.129-156. In: Vandevelde R., Higgins R.J. \& Oevermannn A. (Eds), Veterinary neuropathology essentials of theory and practice. Wiley-Blackwell, West Sussex. 212p. 